\title{
Effect of Reality Therapy in Reducing Examination Phobia among Students of F. C. E. (T.) Bichi, Kano State
}

\author{
Afolabi, Fatai Abayomi (Ph.D)
}

\begin{abstract}
Examination phobia is a psychological condition in which people experience extreme stress, anxiety, discomfort and irrational fear before or during examination. A pre-test-post-test control group design was adopted. The target population comprised of all the NCE III students Two thousand five hundred and eighty students (2580). Simple random sampling technique was used. Test Anxiety Inventory (TAI) was administered on the sample. In all, One Hundred and Twenty (120) NCE III students scored 50 marks and above participated in the study. The students were randomly assigned to experimental group and control group. The experimental group was exposed to reality therapy and the control group was not given any treatment. Two null hypotheses was formulated and tested. T-test for repeated sample was used to analyze the data. The study recommended that professional counselors should utilize the reality therapy intervention as it has proven effective in the reduction of examination phobia.
\end{abstract}

Keywords - Examination, Phobia, Reality, Therapy.

\section{INTRODUCTION}

Examination phobia is a psychological condition in which people experience extreme stress, anxiety, discomfort and irrational fear during or before examination. A little nervousness or tension is healthy for you that it can help you perform your best. But when this tension or stress becomes so excessive that it actually hampers your performance on an examination and then it is called "Examination Phobia" or "Test Anxiety" [15].

Everybody experiences fear or anxiety in life, but the threshold differs from individual to individual. When the fear or anxiety is strong and irrational this can be considered as phobia. According to [8], examination phobia is real, common and affects our whole being. It affects how we feel, how we behave and has some notable physical symptoms. Examination phobia, according to [9] has four different but related components: Cognitive, Emotional, Behavioural and physiological aspects. The cognitive aspects include all of the thoughts that run through the mind before, during and after the dreaded event. For example, thinking: "I have to get an A" on this test; or "I am a failure", lack of confidence, feeling of excessive mental pressure, suicidal ideation, Negative self

Afolabi, Fatai Abayomi (Ph.D), Federal College of Education (Technical) Bichi, P.M.B 3473 Kano State, Nigeria. talk etc. The emotional aspects include the feelings that one experiences related to the anxious event, for example, feeling embarrassed, disappointed or happy etc. On the behavioural aspect, he explained that the body might move differently. For example, a person might write awkwardly, write slovenly, speak incoherently or do things differently, often wrongly, when stressed or anxious, the physiological components might include sweating palms, breathing heavily, rumbling stomach dry mouth, increased urination and increased heart rate.

Moderate anxiety level is a level that does not adversely affect the cognitive, emotional, behavioural and physiological state of an individual. It is relatively normal. [2] asserted that students need moderate dosage of anxiety in order to achieve optimally. It can serve as an important source of motivation. For example, the student who has a slight fear of getting a poor grade in an examination may because of this fear become motivated to use good study habits. In situations like this, phobia can be useful, adaptive and can facilitate achievement. However, phobia becomes a problem when it is excessive, persistent over time and produces significant discomfort for the individual [3]. Students with high level of examination phobia are more likely to employ less effective study strategies and more likely to procrastinate and engage in repetitive memorization strategies [4].

Examination phobia is more intense, more potentially overwhelming, more disruptive and disturbing and it is not helpful [8]. Examination phobia affects the cognitive processes disrupting learning in various stages especially at pre-processing, during processing, right after processing and just before output [13]. It hinders mental and information processes. Causes of examination phobia can be due to irrational and emotive feelings and thinking about a test even before taken it. Lack of preparation, poor time management, poor study habits, unrealistic expectations of parents from their children, parental pressure that cause greater worry and fear of failure and lack of self co-ordination and organization which can lead to a student feeling overwhelmed about the examination. Other reasons include cramming a night before an examination, poor memory and inability to understand and comprehend the test content(s). For some of the students, examination period is an extremely stressful time due to high expectations from the parents, teachers, society and the need for the students to pass before 
they can progress in their academic pursuit. In the students' efforts to meet up with these expectations they could be caught in the grip of fear and anxieties. The examination phobia may lead to students' academic poor performance. Examination phobia if not attended to can hinder student educational progress.

In the field of counseling psychology, there are numerous counseling therapies that enhance adaptive behaviour. These therapies are developed by psychologists and are geared towards the elimination of maladaptive behaviour such as fear, anxiety, neurosis, insecurity and depression among others. Reality therapy is another approach in psychotherapy and counseling. Its approach to counseling and problem-solving focuses on here and now of the client and how to create a better future. Instead of concentrating at length on the past of the client. It emphasizes making decision and taking action and controls one's own life. Typically, clients seek to discover what they really want and whether what they are currently doing (how they are choosing to behave).

Reality therapy is actually bringing the clients nearer to, or further focuses on facilitating the clients to become aware of , and if necessary, change his/her thoughts and actions (Glasser,1980). It is therefore necessary to guide the students to realize that in most cases examination phobia does not help them to perform well in examination and that they need to reduce their examination phobia by facing the reality of academic pursuit in life and that examination is what they must come across in their upward movement in academic career and they must handle it without anxiety.

It is therefore necessary that students need to be helped by way of counseling them on how to face the reality of academic progress in life. Through this, students will be able to handle examination phobia. The school counselors are expected to help students in this area.

Studies such as [1], [11], [6], [12], [14] have employed different group counseling strategies to reduce examination anxiety among students. The basic assumption by this researcher is that if students are helped to face the reality that they cannot do without examination, this will help them to gain the necessary composure that will help the students to be able to handle examination phobia.

\section{Statement Of The Problem}

Phobia is an emotional problem and if not attended to professionally, could be carried over to examination situations. This can lead to examination phobia which can cause academic failure or poor academic performance resulting from withdrawal syndrome, cultism, delinquency, crime and low self-esteem. The identified causes of examination phobia and its prevalence prompted the researcher to conduct this experimental study of effect of reality therapy in reducing examination phobia among students of Federal College of Education (Technical) Bichi, Kano State.

\section{PuRpose OF THE STUDY}

The purpose of the study was to examine the effect of Reality
Therapy (RT) to students and finding out its relative efficacy on the reduction of examination phobia among students of Federal College of Education (Technical) Bichi, Kano State

\section{RESEARCH HYPOTHESES}

The following null hypotheses were generated to guide the study:

1) There is no significant difference in reducing examination phobia between students exposed to Reality Therapy (RT) intervention and those in the control group.

2) There is no significant difference in the effect of Reality Therapy (RT) intervention in reducing examination phobia among male and female students.

\section{RESEARCH DESIGN}

The design for this study was the true experimental pre-test-post-test control group design. This design was chosen because it permits the investigator to study change. The main strength of this design is the initial randomization, which assures statistical equivalence between the groups prior to experimentation [5].

\section{Population Of The Study}

The target population of this study comprised of all the NCE III students of the Federal College of Education (Technical) Bichi, Kano State, which consisted of Two thousand Five Hundred and Eighty (2580) students (Federal College of Education (Technical) Bichi, 2016/17 Session).

\section{SAMPlE AND SAMPLING TECHNIQUES}

A total of Three Hundred and Forty six (346) NCE III students were randomly selected with the use of simple random sampling techniques, taken into consideration the strata that exist within the population of the study. The selection was based on the recommendation of [10]. The researcher identified one hundred and twenty (120) test anxiety prone NCE III students from Three Hundred and Forty six (346) samples with the use of pre-test examination on Test Anxiety Inventory (TAI) developed by [16].

\section{INSTRUMENTATION}

For the purpose of this study, an instrument tagged Test Anxiety Inventory (TAI) and treatment intervention was used. This include:-

- Adopted version of Test Anxiety Inventory (TAI) developed by [16] to measure test anxiety.

- $\quad$ Reality Therapy (RT) treatment developed by [17]. This was used as treatment intervention for reducing examination phobia.

Test Anxiety Inventory (TAI) is a self report inventory designed to measure test anxiety as a situation-specific personality trait. The instrument comprises of 20 items or statements that measure test anxiety under two components that is Worry (W) and Emotionality (E). These two components formed test anxiety inventory and the respondents indicated on a 4 point Likert Scale how often they experience the feeling 
described in each statement with awarded scores: Never (1), Sometimes (2), Often (3), Always (4). The psychometric of the TAI was established which indicated that content validity was used while a test re-test reliability co-efficient of 0.80 was obtained for the instrument with the use of 76 subjects over a period of three weeks interval [16].

\section{VAlidATION Of TeSt ANXIETY INVENTORY (TAI)}

The researcher re-validated the TAI so as to determine the psychometric properties of the instrument. The validity of the TAI was determined with the use of content validity, the scale since the 20 items selected were based on the responses of 55 subjects. Factor analysis on the responses of the 55 subjects using the principal components analysis with varimax rotation yielded 2 factors. The factors are Worry (W) and Emotionality (E). All the 20 items had minimum factors loading of 0.40 . The reliability of the TAI was also determined with the use of test re-test reliability co-efficient administered after three weeks through a pilot study on $55 \mathrm{NCE}$ III students from F.C.E Kano, 0.89 was obtained which is considered adequate and adjudged appropriate for the study.

\section{Procedure For TREATMENT}

In this study, pre-test was administered to identify students that are test anxiety prone. The students who scored 50 marks and above in the TAI were considered to have high level of test anxiety while those who scored below 50 marks were not considered for the study. In all, 120 NCE III students scored 50 marks above participated. The students were randomly assigned into two groups (1 treatment group and control group). Reality therapy was administered to the experimental group but the control groups were only pre-tested for identification purpose without being exposed to any given treatment intervention. The treatment period lasted for seven weeks. After this, a post-test was administered to both experimental and control groups.

\section{Hypotheses Testing}

$H_{01}$ : There is no significant difference in reducing examination phobia between Students exposed to Reality Therapy intervention and those in the control group.

This hypothesis was tested by subjecting the post-test scores of the two groups to t- test analysis as presented in table 1.

TABLE I: DIFFERENCE IN THE EFFECT OF REALITY THERAPY INTERVENTION IN REDUCING EXAMINATION PHOBIA AMONG STUDENTS OF FEDERAL COLLEGE OF EDUCATION (TECHNICAL) Bichi, Kano State

\begin{tabular}{lcccccc} 
Group & $\mathrm{N}$ & Mean & $\begin{array}{c}\text { Standard } \\
\text { Deviation }\end{array}$ & t-Cal & P-value & Decision \\
\hline RT & 60 & 16.08 & 1.59 & 44.20 & .000 & Rejected \\
Control & 60 & 25.37 & .486 & & & \\
\hline
\end{tabular}

Table 1: Shows a paired sample t-test indicating that scores were significantly higher for the control group $(M=25.37$, $\mathrm{SD}=.486)$ then for the Reality Therapy group $(\mathrm{M}=16.08$, $\mathrm{SD}=1.59) \mathrm{t}$-cal (44.20), $\mathrm{P}<.001, \mathrm{~d}=5.71$. This indicates that there was difference in the effect of Reality Therapy intervention in reducing examination phobia between those in the Reality Therapy group and those in the control group. Therefore, H01 which stated that there is no significant difference in the examination phobia of the levels of students exposed to reality therapy and those in the control group is not accepted.

$H_{O 2}$ : There is no significant difference in the effect of Reality Therapy Intervention in reducing examination phobia among male and female students.

This hypothesis was tested by subjecting the post-test scores of the male and female students to t-test analysis as presented in table 2 .

TABLE II: DIFFERENCE IN THE EFFECT OF REALITY THERAPY INTERVENTION IN REDUCING EXAMINATION PHOBIA AMONG MALE AND FEMALE STUDENTS OF Federal College of EduCATION (TeChNiCAL) Bichi, Kano State

\begin{tabular}{lcccccc} 
Variables & $\mathrm{N}$ & Mean & $\begin{array}{l}\text { Standard } \\
\text { Deviation }\end{array}$ & $\mathrm{t}-\mathrm{Cal}$ & $\mathrm{P}$-value & Decision \\
\hline Male & 60 & 19.6 & 3.49 & & & \\
Female & 60 & 18.6 & 3.26 & 1.21 & .231 & Accepted \\
\hline
\end{tabular}

From table 2 above, a paired sample t-test indicated that scores were significantly higher for the male students $(\mathrm{M}=19.6, \mathrm{SD}=3.49)$ than for the female students $(\mathrm{M}=18.6$, $\mathrm{SD}=3.26, \mathrm{t}-\mathrm{cal}=1.21, \mathrm{P}>.05, \mathrm{~d}=0.15$. This indicates that there was no difference in the effect of Reality Therapy intervention in reducing examination phobia among male and female students in Federal College of Education (Technical) Bichi, Kano State. Therefore, H02 which stated that there is no significant difference in the effect of Reality Therapy intervention in reducing examination phobia among male and female students in F.C.E (T.) Bichi, Kano State.

\section{Discussion OF FindingS}

The primary aim of this study was to find out the effect of treatment (Reality Therapy) in reducing examination phobia, thereby improving students' performance in examinations. The experimental treatment (Reality Therapy) actually had effect on the level of students' examination phobia.

The study discovered that there was a significant difference in the effect of Reality Therapy intervention in reducing examination phobia between those in the experimental and control group. The study confirmed the findings of [17] that a statistically significant difference was found on the effect of Reality Therapy employed on reduction of examination phobia among students. The fact that, the treatment had effect on the level of examination phobia among students could be due to what they experienced during the period of exposure to the treatment sessions.

The study also discovered that there was no significant difference in the effect of Reality Therapy intervention in reducing examination phobia among male and female students. The hypothesis was confirmed by the findings showing no statistically significant difference in the effect of treatment on the level of examination phobia among male and 
female students. The result corroborated the findings of [17] who confirmed that gender has no significant influence on the effect of reality therapy on the level of examination anxiety among students. This result may be attributed to the fact that the students (both male and female) in the Reality Therapy group adjusted equally when exposed to the same reality therapy intervention on how to handle examination phobia. The result further confirmed the efficacy of reality therapy technique on the level of examination phobia. The result did not support general assumption that females tend to exhibit severe fear and anxiety more than their male counterparts.

\section{CONCLUSION}

The following conclusions could be made from the results of the findings of this study:-

- There is a significant difference in the effect of reality therapy intervention in reducing examination phobia between those in the reality therapy group and those in the control group.

- There is no significant difference in the effect of reality therapy intervention in reducing examination phobia among male and female students.

\section{RECOMMENDATIONS}

Based on the efficacy of reality therapy intervention, the researcher recommends the following:-

Professional counselors should utilize the reality therapy intervention as it has proven effective in the reduction of examination phobia among the students exposed to it.

\section{REFERENCES}

[1] Adeola, A.O (1987). The Effectiveness of the Relaxation Procedure in Anxiety Management. Nigerian Journal of Educational Psychology. 2(1), 23-29

[2] Aremu, A.O (2004). Psychological and Sociological Determinants of Academic Achievement of Nigerian Adolescent. Ife PsychologiA: International Journal of Psychology in Africa. 12(2), 149-161. https://doi.org/10.4314/ifep.v12i2.23651

[3] Busari, A.O (2000). Stress Inoculation Training and Self-statements Monitoring Techniques in the Reduction of Test Anxiety among Adolescent Underachievers in Ibadan Metropolis, Nigeria. Ph. D Thesis, University of Ibadan.

[4] Cassady, J.C (2004). The Impact of Cognitive Test Anxiety on Test Comprehension and Recall in the Absence of External Evaluation Pressure. Applied Cognitive Psychology 18,131-136. https://doi.org/10.1002/acp.968

[5] Christensen, B.L (1997). Experimental Methodology (Seventh Edition) Boston; Allyn and Bacon Inc.

[6] Egbochucku, E.O (2005). Differential Effectiveness of Systematic Desensitization and Rational Emotive Therapy in the Reduction of Test Anxiety. Journal of School of Languages. 11(2), 25-50

[7] Glasser, W (1980). Reality Therapy; A New Approach to Psychiatry. New York: Harper \& Row

[8] Ipaye, B (2005). Study Guides and Learning. Strategies in Open and Distance Learning. Lagos: Chayoobi Publishers.

[9] King, J (2000). How Does Test Anxiety Affect you? Retrieved on $20^{\text {th }}$ April, 2018. www.gwired.gwu.edu/ counsell
[10] Krejcie, R \& Morgan, D. W (1970). Determining Sample Size for Research Activities. Educational and Psychological Measurement, The Research Advisor, (2006). https://doi.org/10.1177/001316447003000308

[11] Makinde, B.O (2000). Behaviour Modification Strategies as a tool to reduce fears and Anxiety in Children and Youth in Lagos State. West African Journal of Counselling and Psychotherapy 1(2),41-51

[12] Obodo, B.O (2005). Effects of Systematic Desensitization (SD) Therapy on the Reduction of Test Anxiety among Adolescents in Nigerian Schools. Journal of Instructional Psychology.

[13] Okoli, C.E (2002). Techniques of Behaviour Modification. Lagos: Belienu Press \& Publishers.

[14] Osiki, J.O \& Busari, A.O (2006). Effects of Self-statements Monitoring Techniques in the Reduction of Test Anxiety among Adolescent Underachievers in Ibadan Metropolis. The Counsellor. 2 (5), 45-52

[15] Sindhu, P (2015). A Theoretical Approach to Management of Examination Phobia among High School Students. The International Journal of Indian Psychology. 2 (4),73-81.

[16] Spielberger, C.D (1980). Test Anxiety Inventory. Preliminary Professional Manual, Palo Alto: Consulting Psychologists Press.

[17] Yusuf, A.F (2009). Comparative Effectiveness of Relaxation Technique and Reality Therapy in Reducing Examination Anxiety among Secondary School Students in Osogbo, Nigeria. An Unpublished Ph. D Thesis, University of Ilorin.

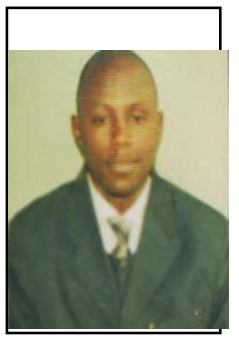

He was born in Lagos, Nigeria on 10th of October, 1973. He obtained his First degree (1999), Master degree (2003) and Doctoral degree (2013) from Usmanu Danfodiyo University Sokoto, Nigeria. He specializes in Counselling Psychology.

He works with the Federal College of Education (Technical) Bichi, Kano State, Nigeria presently as a Senior Lecturer. He is the current Head of Department, counseling psychology and at the same time current Sub-dean, School of General Education. He has published a book internationally titled "Effectiveness of rational emotive behaviour therapy and study skills training in reducing text anxiety among students published in Germany by Lap Lambert Academic Publishing.

Dr. Afolabi Fatai Abayomi is the Editor-in-Chief of Bichi Journal of Educational Review. 